\title{
Integration and Co-Construction of School Sports Culture and Community Sports Culture
}

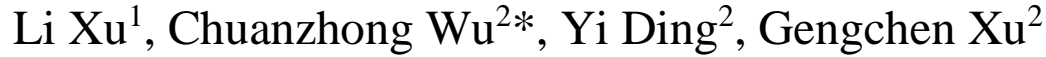 \\ ${ }^{1}$ Department of Logistics Management, JiangSu Ocean University, Lian Yungang 222005, China \\ ${ }^{2}$ Innovation and Entrepreneurship Department, JiangSu Ocean University, Lian Yungang 222005, China \\ *Corresponding author. Email: 13450864@qq.com
}

\begin{abstract}
Integration of school sports culture and community sports culture is the responsibility of education. It can improve the quality of personnel training and social services, can realize the interactive sharing and effective use of resources, create social benefits and gain more. Social support is in line with the common interests of both and is a new historical mission for the development of sports in China. The integration of school sports culture and community sports culture is a systematic project. The integration of school sports culture and community sports culture aims to create social, educational, economic and fitness values, explore the operational mechanism and development model of the "schoolsocial" sports culture integration, and realize school sports and community sports.
\end{abstract}

Keywords: Sports Culture, School Sports, Community Sports, Integration, Construction.

\section{PREFACE}

Culture is a kind of spiritual power, is the creation, inheritance and promotion of the inner spirit in human society. Through the whole process of human survival, has profound impact on the development of human history. Sports is cultural phenomenon, is the important part of human civilization, in the long historical process, through the survival of the fittest competition and inheritance. School, college and university are the gardens of talent cultivation and main position of education. It undertakes historical responsibility of cultivating high-quality talents with comprehensive quality and all-round development. In the new era of scientific and technological revolution, science and technology and humanities complement each other, and education also ushered in a new historical mission. School education is the frontier fortress of cultural inheritance, and school physical education is an important part of school education. The integration of school sports culture and community sports culture for common development, on the one hand, is the responsibility of education, can improve the quality of personnel training and social services, on the other hand, can realize the interactive sharing and effective use of resources, can create social benefits and get more social support, in line with the common interests of both, is the new mission of China's sports development.
The effective integration of community sports resources and school sports resources, the integration of school sports culture and the common development of community sports culture have become an important development mission of Chinese sports in the new era. This paper studies the concepts of school sports and community sports, discusses the structural elements and development contents of school sports culture and community sports culture. On this basis, it uses dialectical analysis to study the feasibility and value significance of the fusion development of school sports culture and community sports culture, researchs the methods and strategies of mutual construction of school sports culture and community sports culture, and studies the relationship between school sports culture and community sports culture. In order to solve the problem of making school sports and community sports serve "sunshine sports project" and "comprehensive fitness plan", this paper discusses the mechanism of Sports Culture Collaborative Construction and common development between school and community.

\section{CONNOTATION OF SCHOOL SPORTS CULTURE}

The school is the frontier fortress of cultural heritage, the garden of talent training, and the "service station", "think tank", "talent pool" and "innovation source" of social development. It shoulders the 
historical mission of cultivating high-quality talents with comprehensive quality and all-round development. The inheritance of advanced culture, the popularization and promotion of science and technology, and the cultivation of moral cultivation all need to take the school as the center and radiate to the public.

School culture is the general term of campus characteristic culture and spirit with students as the main object and cultural and sports activities as the carrier, including school spirit, school appearance, class spirit, study style, teacher-student relationship, campus public opinion, campus atmosphere, school rules and regulations, student behavior norms, etc. School education is not only classroom education or examination evaluation, but also the educational significance and value of campus culture. Campus culture is a kind of environmental power, a power of collective wisdom, and an embodiment of the strength of running a school. Based on the correct orientation of the socialist core values and the construction of the school's characteristic cultural atmosphere, let the students participate in it, bathe in the sunshine and rain of the socialist spiritual culture, absorb the nutrients of collective wisdom, and then improve the students' learning ability, organizational ability, management ability, practical ability, innovation and creativity.

School sports culture is the material and spiritual civilization created by teachers and students in the practice of school sports education, including campus sports spirit, sports system, sports behavior culture and sports traditional culture. School sports culture is an important part of campus culture and one of the important educational forces for students to form good personality. Strengthening the construction of school sports culture will help to optimize the overall sports environment, improve the quality of school campus culture construction, and improve the quality of school personnel training. In order to develop sports, a school should choose suitable sports items according to its own strength and existing sports resources, gradually form a characteristic sports culture system, and then create a characteristic brand project.

\section{CONNOTATION OF COMMUNITY SPORTS CULTURE}

"Community" means a group life with Social Union established in a certain geographical area. Community sports is an integral part of social sports. It is a spontaneous physical exercise activity of community residents. It has the characteristics of fitness, entertainment, autonomy and public welfare. It can enrich the cultural life of residents, improve the quality of life, improve interpersonal relations, and promote the prosperity and development of the community.

Community sports is the carrier of the integration of "school, family and society", and community sports is the natural continuation of school sports. To strengthen the construction of school sports is to maximize the development and utilization of school sports resources, promote the achievements of school sports construction to the society, integrate the resources of school sports and community sports, realize the fusion development of school sports culture and community sports culture, promote the sustainable development of school sports, and make contributions to the construction of social spiritual civilization.

Community sports culture is a kind of sports culture phenomenon formed in the construction and development of community sports (Tian Tong, 2006). Community sports culture refers to the sum of all the sports cultural activities of community residents in the local area. It is the sports material and spiritual wealth created by people in the long-term life practice process, including community sports assets, sports atmosphere, mass sports consciousness, sports values, sports behavior and sports activities. [1] In other words, the social mainstream culture will determine the nature, content and direction of school sports culture and community sports culture. With the increasingly rich material life and the pursuit of a better life, social sports, especially community sports, will become the main content of people's leisure life. Community sports play an increasingly important role in parent-child relationship, fitness and entertainment, and interpersonal communication.

\section{INTEGRATION OF SCHOOL SPORTS CULTURE AND COMMUNITY SPORTS CULTURE}

In view of the problem of how to integrate the development of school sports culture and community sports culture, this paper discusses the content system of the interactive development of school sports culture and community sports culture from the perspectives of pedagogy, demography, sociology and economics.

(1) In order to create characteristic sports cultural activities and win social recognition, schools need to interact and integrate with community sports. Community sports can provide a broader platform for school sports. Community sports talents can guide school sports cultural activities, improve the level of sports skills, promote the further improvement of PE Teachers' professional quality and professional quality, guide students to actively participate in sports, spread campus sports culture, and enhance the friendship between school and local. School sports can enrich the content of community sports, provide convenient facilities for community sports, improve the enthusiasm of community people to participate in sports activities, and cultivate reliable sports talents for the future development of community sports. 
(2) The research on the integration and development of school sports culture and community sports culture is conducive to the integration and exertion of national cohesion, the enhancement of the connection and emotion between the masses, and the formation of a harmonious social and cultural atmosphere. Based on the theoretical research of school and community sports, this paper studies how schools or communities cultivate the backbone of social sports, how to drive the masses to consciously participate in sports activities, how colleges and universities realize the socialization of students, how to achieve the sound development of school sports and community sports, and how to build the construction mechanism of school sports and community sports, and how to study the guiding factors for the interactive development of "school community", Design the platform of "school community" to build sports culture together, and construct the operation mechanism and integrated development mode with promotion value.

(3) With the increasing proportion of the elderly population in China's population, the value of social sports has become increasingly prominent. Based on the general physical test indicators, this paper studies the health status and characteristics of the community population and school students, and explores the most suitable sports items for people of different ages and different health conditions according to the project fitness value, and establishes the project classification system. In this way, we can promote the healthy development of the whole community sports, and promote the healthy development of the whole nation sports.

(4) The effective integration of community sports resources and school sports resources can give full play to the health and entertainment functions of sports, promote the development of community sports economy, and provide continuous power for the sustainable development of national sports. Students' sports behavior can strengthen the status of school physical education and enrich students' after-school life. Community residents' sports behavior can improve the quality of amateur cultural life and serve for local development and economic prosperity. Based on the analysis of the cost and benefit, this paper studies how to solve the contradiction of the utilization of school and community sports resources, realize the optimal allocation of resources, create a win-win or multi win situation between school and community, and explore the long-term mechanism of mutually beneficial cooperation between school sports and community sports.

\section{INTEGRATION MECHANISM OF SCHOOL SPORTS CULTURE AND COMMUNITY SPORTS CULTURE}

In order to explore the integration and development of school sports culture and community sports culture, we should first establish a long-term mechanism for the common development of school sports and community sports. It is suggested to take the "cost-benefit" research as the premise, that is, to create social benefits, educational value, economic value and fitness value as the goal, and to deeply explore the interactive elements of school sports and community sports resources This paper studies the internal relationship between human resources and facilities, analyzes the interactive relationship between managers, organizers, implementers and beneficiaries, and explores the interactive sharing mechanism and operation mode of school sports and community sports resources.

\subsection{Complementary Resources to Expand Development Space}

The development of school sports can not be separated from the social demand for sports. There is a huge space for the development and utilization of school sports resources in serving the society. School sports venues, fitness equipment and other hardware facilities resources are very rich, in school education is to meet the needs of sports teaching, extracurricular activities, but in addition to teaching and sports activities time, school sports venues, facilities and other hardware resources are idle stage, especially holidays, weekends and evening time, these time is exactly the community residents for sports and fitness activities It's the best time. Through the study of sports skills, students can initially master the basic physical exercise methods, understand the importance of lifelong physical exercise, and lay a solid foundation for the better development of mass sports in the future, so as to better promote the development of community sports. PE teachers can also participate in the construction of community sports culture, lead students to participate in community sports activities, meet students' sports interests, enrich sports knowledge and improve sports skills.

\subsection{Active Sports Culture Atmosphere}

School sports culture needs to be recognized by the society, so it needs to go out of the campus and get a broader space for development. At the same time, school sports culture should integrate with community sports culture for common development. Schools can also create a new situation of the inclusive development of school and community sports culture with the help of human and financial resources of community sports. School sports atmosphere and sports culture atmosphere are relatively mature, but there is still room for 
improvement. School sports and community sports can establish sports exchange and interaction platform, so that teachers and students can participate in the construction of community sports culture in their spare time, and promote the development of community sports culture. The development of community sports is helpful to enrich the contents and methods of school sports teaching, so that school sports talents can get the stage to display their talents. It can also attract more sports fans, parents and family sports activities, which can form a good atmosphere for the construction of sports culture.

\subsection{Create A Win-win Situation through Collaborative Construction}

School sports and community sports should cooperate to build, learn from each other and create a win-win situation. The key lies in the promotion of sports culture and the development and utilization of resources. It is suggested that research should be carried out around the two major content systems of school sports and community sports, aiming at social benefits, educational value, economic value and fitness value, to explore the curriculum resources of school sports and community sports resources, to find the construction elements of interactive platform, to optimize the combination, to establish a scientific management mechanism, to create a good humanistic and social environment, and to explore the relationship between school sports and community sports The influencing factors and guarantee mechanism of the development of educational integration. For example, in the community to establish school sports social practice base, the school sports club construction and practice base construction, the establishment of "Community Youth Sports Center", "community sports guidance center", "sports injury rehabilitation center".

\section{CONCLUSION}

School sports and community sports are two important parts of sports in our country. Their development is symbiotic and related, which is more related to the physical quality, physical and mental health and happy life of every citizen in our country. School physical education is an important foundation of social sports. It belongs to the predecessor category of social sports. It is the soil of growth and social sports, and serves for social sports. Community sports resources and school sports resources complement each other, learn from each other, effective integration will help to improve the quality of national sports development. The integration of school sports culture and community sports culture for common development is one of the important missions entrusted by the times to China's sports cause. It can improve the quality of national education, improve the national physique, and promote the harmonious and steady development of society. It carries the ideal and desire of national education, and is an indispensable piece of jigsaw puzzle in the great rejuvenation project of the Chinese nation.

It is a systematic project to integrate and develop school sports culture and community sports culture. What needs to be solved is not only the sharing and utilization of sports venues, equipment, facilities and teachers, but also the inheritance and promotion of sports culture, sports knowledge and folk sports. This is a new direction of China's sports development at this stage and an important proposition to be solved urgently in sports research. The fusion development of school sports culture and community sports culture should aim at creating social benefits, educational value, economic value and fitness value, explore the operation mechanism and development mode of the fusion development of "school community" sports culture, realize the mutual sharing and common development of school sports and community sports resources, and make school sports and community sports truly serve as the "sunshine sports project" and "community sports" "Comprehensive fitness program" service.

\section{ACKNOWLEDGMENTS}

Thanks to Professor Korobeynikava Lesia of the National University of physical education and sports of Ukraine. Thanks to Professor Chen Jinsong of Jiangsu Ocean University of China, thanks for your support and help.

\section{REFERENCES}

[1] Tian Tong. The construction of community sports culture is the foothold of promoting the harmonious development of community sports [J]. Sports science, 2006 (4): 50-53

[2] Wang Yanyuan. Research on the coordinated development of community sports culture and school sports resources [J]. Journal of Inner Mongolia Normal University (EDUCATION SCIENCE EDITION), 2013 (9): 150-152

[3] Tan mingqiong. Current situation and Countermeasures of school participating in community sports culture construction [D]. Master's thesis of Capital Institute of physical education, 2006 